\title{
Influence of coupling agents on the adhesion force of dissimilar overmolded polymers: a digital image correlation analysis
}

\author{
Luciano Pisanu ${ }^{1}$, Josiane Barbosa ${ }^{2}$, Pedro Bamberg ${ }^{2}$, Bernd Marx ${ }^{3}$, \\ Alexander Schiebahn ${ }^{3}$, Ricardo Souza ${ }^{4}$, Marcio Nascimento ${ }^{4}$
}

\author{
${ }^{1}$ UFBA - Federal University of Bahia, Escola Politécnica, R. Aristides Novis 2, Federação. 40170-115. Salvador, Bahia, \\ Brazil. \\ ${ }^{2}$ SENAI-CIMATEC, Institute of Innovation for Forming and Joining of Materials, Av. Orlando Gomes 1845, Piatã. \\ 41650-010, Salvador, Bahia, Brazil. \\ ${ }^{3}$ RWTH Aachen University, Welding and Joining Institute (ISF), Pontstraße 49, 52062 Aachen, Germany \\ ${ }^{4}$ University of Aveiro, 3810-193, Campus Santiago, Aveiro, Portugal. \\ e-mail: luciano.pisanu@ fieb.org.br, josianedantas@ fieb.org.br, pedro.bamberg@ fieb.org.br, marx @isf.rwth-aachen.de, \\ schiebahn@isf.rwth-aachen.de,rsousa@ua.pt,mlfn@ufba.br
}

\begin{abstract}
The increase in the technical and functional requirements of plastic items has led the development of multimaterials. To achieve a good performance in the adhesion of dissimilar materials, in this case, polypropylene and coconut fiber composites, it is fundamental to understand the phenomena related to the specific interface. This work aims to evaluate the adhesion force of different multi-materials, namely between overmolded polymer-coconut composites using the digital image correlation (DIC) technique. First, coconut fiber composites were prepared using three different coupling agents, then they were overmolded with polypropylene. The results show that coupling agents have a positive influence increasing the mechanical properties of such multi-materials under tensile stress. The Lagrange vectors obtained by DIC analysis identified higher stress concentration at the joint edges, where the occurrence of surface cracks led the samples to fail in the region close to the overlap.
\end{abstract}

Keywords: composite structures; digital image correlation; polymers adhesion; multi-component injection molding.

\section{INTRODUCTION}

Multi-component injection processes involving the adhesion of different materials and properties in a single product have been gaining attention in industry. They are being widely used as they enable a high degree of automation without additional assembly stages or post processing [1]. There is a range of multi-component processes, which can be used. The chose depends mainly on the complexity, the application and the cost of the product. The five most known multi-component injection processes are: co-injection, sandwich molding, bi-injection, overmolding and multi-shot molding [2].

The overmolding process, used in this work, is a complex process that uses a compound mold to produce a multi-component product. The first material is injected into a mold by the conventional technique of single material molding (SMM), and then the mold turn $180^{\circ}$ around its center axis to receive the second material, that is thus combined with the first [3]. The presence of a molded two-phase component, promotes a new and different procedure when compared with traditional injection processes. Despite its advantages, some drawbacks can be highlighted, such as incompatibility between materials, interactions among cooling systems of different phases, location of the injection points, polymer moldability and ejection problems [1].

To promote good adhesion between dissimilar materials, some information from bonding interface must be known previously, which can be considered a sum of physical and chemical forces at the contact surface that overlap and influence each other [4]. The physical forces are basically produced by mechanical interlocking between materials, including pores and roughness at the interface. According to da Silva et al. [5] on the mechanical interlocking theory, rough surfaces provide higher adhesion; however, it relies on good 
wettability between the surface of both materials. For instance, the existence of pores at the interface which can lead to inefficient joining of the materials should be avoided.

Other theories about the adhesion of polymers consist of electrostatic forces, adhesion by adsorption, diffusion (which encompasses the phenomenon of auto diffusion and coupling by entanglement), cooperativity and reptation theory, which have been applied in studies of adhesion between polymers [6,7,8].

The adhesion phenomenon between two dissimilar materials is complex, and it is difficult to predict the exact nature and quality of the interface. If the materials are dissimilar, such as polymers and composites, and if they are incompatible, then, only a mechanical interlock can successfully hold them together. If the polymers and composites are compatible, as is desirable for an overmolding operation, the joint interface should reach a temperature sufficiently high to ensure adhesion. According to the literature, the adhesion property depends mainly on two factors: intermolecular bonds and surface tension [9].

A requirement for good adhesion is the adhesive being able to reach most of the adherend. In the present case, both surfaces are not uniform as the composite surface presented several fissures and pores as the main defects. To ensure a good adhesion, a high wettability is necessary so that the added material can spread over the adherend surface, thus optimizing adhesion, covering a larger area (as much as possible) and minimizing or even eliminating pores [7]. Incompatibility between fiber and polymer matrix is a major problem for interfacial adhesion and is of critical importance for desirable mechanical properties of the resulting multi-material. Coupling agents are designed to improve the chemical compatibility between hydrophobic plastic and hydrophilic fiber components, promoting improved adhesion and assisting the process [6,10,11]. The coupling agents are intentionally designed to contain chemical functional groups that can react with hydroxylated inorganic surfaces, producing covalent bond linkages. The coupling agent then acts as a bridge to bond the fiber to the polymer matrix with a chain of primary bonds that, in principle, could be expected to lead to the strongest interfacial bond [11].

The Digital Image Correlation (DIC) technique dates back to 1950s and 1960s proposals initially involving character recognition, microscopy, medicine / radiology, and aerial photographs [12]. It appears that the first article using DIC in polymers was published in 1997, more precisely in the polymethyl methacrylate mechanical assay between -40 and $125^{\circ} \mathrm{C}$ [13].

\section{MATERIALS AND METHODS}

For the adhesion strength study, a specific injection mold was developed to provide samples with variable overlap. One sample is illustrated in Figure 1(a/b). It was based on the measurements of ISO 527 Type 1A specimen.

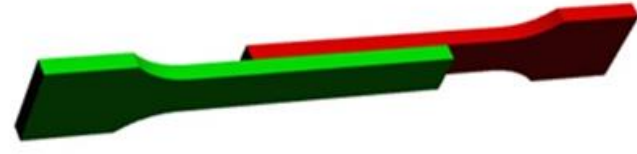

(a)

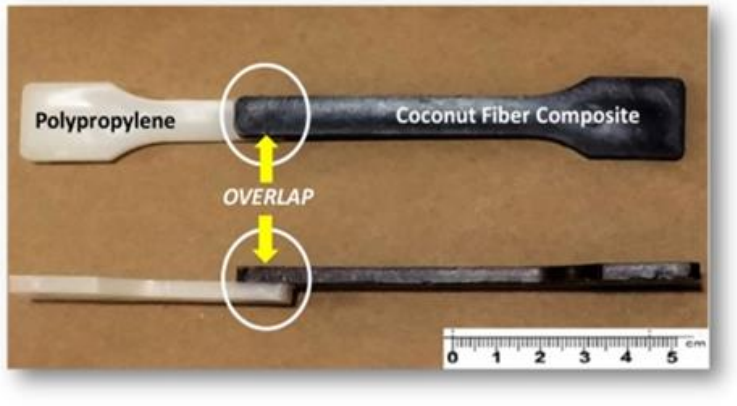

(b)

Figure 1: a) Sample model in perspective with large overlap between dissimilar materials. $b$ ) Injected specimens with overlap area of $120 \mathrm{~mm}^{2}$ between dissimilar materials. 


\subsection{Preparation of the composite}

To evaluate the influence of the coupling agents on the adhesion strength between dissimilar materials, more specifically a composite of a copolymer polymeric matrix with coconut fiber overmolded with polypropylene (PP), four formulations of composites with dry coconut fibers which were prewashed and crushed in a knife mill were prepared. The selected PP was EP 440L purchased from Braskem, an ethylene heterophasic copolymer with flow rate of $6.0 \mathrm{~g} / 10 \mathrm{~min}$ according to ASTM D 1238. The coupling agents used were: i) Orevac CA 100, a functionalized polypropylene (PP) with maleic anhydride (indentified as PPOCA100); ii) Orevac 18507, a polyethylene (PE) functionalized with maleic anhydride - both supplied by Arkema (PPO18507); iii) Cesa ${ }^{\circledR}$ Mix PEA0601031, of the Clariant Company, which consists of titanate-functionalized polyethylene that uses stearamine as a lubricant (PPCM). This particular coupling agent was customized for a specific application in composites with natural fibers at SENAI CIMATEC. Table 1 presents the contents of coconut fiber and the coupling agent, which are relative to the total mass of the composite sample (30wt.\%), with the percentage of $6 \mathrm{wt} . \%$ additive associated to the fiber content, resulting $1.8 \mathrm{wt} . \%$ total mass.

Table 1: Formulations used in the sample preparations (wt.\%).

\begin{tabular}{l|l|l|l|l|l}
\hline Formulations & PP EP 440L & Coconut Fiber & $\begin{array}{l}\text { Orevac } \\
\text { CA 100 }\end{array}$ & $\begin{array}{l}\text { Orevac } \\
\mathbf{1 8 5 0 7}\end{array}$ & Cesa® Mix \\
\hline PPFC & 70 & 30 & - & - & - \\
\hline PPOCA100 & 68.2 & 30 & 1.8 & - & - \\
\hline PPO18507 & 68.2 & 30 & - & 1.8 & - \\
\hline PPCM & 68.2 & 30 & - & - & 1.8 \\
\hline
\end{tabular}

Legend: PP EP 440L -Polypropylene; PPCF - Composite of polypropylene and coconut fiber without coupling agent; PPOCA100 - Composite of polypropylene and coconut fiber with Orevac CA 100 as coupling agent; PPO18507 - Composite of polypropylene and coconut fiber with Orevac 18507 as coupling agent; PPCM - Composite of polypropylene and coconut fiber with $\mathrm{Cesa}^{\circledR}$ Mix as coupling agent.

After weighing the formulations, the premix was dosed at the main feed point of a corotating screw extruder manufactured by Imacom, model DRC 30:40 IF with thread diameter of $30 \mathrm{~mm}$ and $L / D$ ratio $=40$ between length and diameter. The processing conditions for these composites were: i) screw speed: $140 \mathrm{rpm}$; ii) feeding speed: $8 \mathrm{rpm}$; iii) mass temperature: $184{ }^{\circ} \mathrm{C}$. The thread profile used can be considered typical for the production of composites with vegetable fibers and is composed of two mixing zones formed with kneading blocks of $45^{\circ}$ and $90^{\circ}$ and the other elements designed to the transport of material.

\subsection{Preparing injected and overmolded samples}

After the composite formulation step, the materials were dried at $100{ }^{\circ} \mathrm{C}$ during eight hours and used to prepare the specimens. In this process a ROMI model Primax $100 \mathrm{R}$ was used. The injection of the specimen was given at a pressure of $950 \mathrm{bar}, 120 \mathrm{~cm}^{3} / \mathrm{s}$ and a temperature of $200{ }^{\circ} \mathrm{C}$ of the molten material.

The overmolded samples were made in an ARBURG Allrounder 370S injection molding machine using two injection units: a horizontal one named "Injection Unit 1" and a vertical one named "Injection Unit $2 "$. With the aid of a rotating plate, specimens with an intersection of $120 \mathrm{~mm}^{2}$ (the overlap area) were obtained as illustrated in Figure 2.

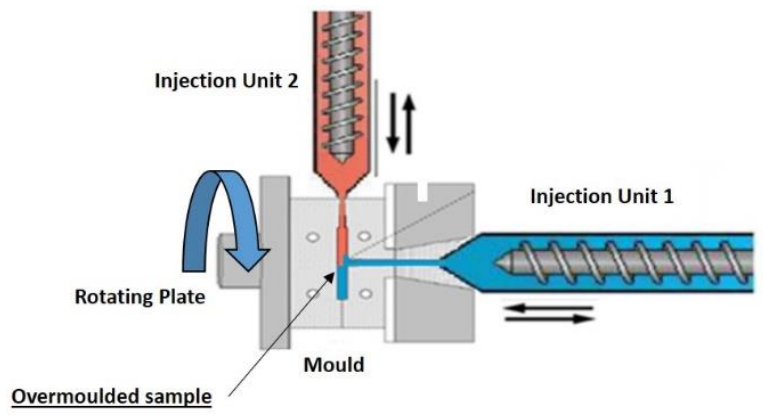

Figure 2: Machine for overmold injection. Adapted by Authors. 
The conditions adopted to open the mold and to promote the rotation of the plate was similar to those adopted by industry, i.e. wait until the material is completely solidified. Figure1 $(b)$ shows the profiles of specimens injected with dissimilar materials.

By means of a pre-established control on the variables of the injection process, samples of the overmolded and encoded materials were obtained as shown in Table 2. Unit 1 was responsible for injecting the composite material with coconut fiber, which justifies the gradient of increasing temperature from $180^{\circ} \mathrm{C}$ to $210^{\circ} \mathrm{C}$ ( 5 zones), with the intention of not degrading the vegetable fiber. In unit 2 , the pressure and the injection flow were stepped in three stages in order to avoid flashes on the part that had been injected in the first stage.

Table 2: Parameterized values of the injection molding for the formulations of the previous table.

\begin{tabular}{l|l|l}
\hline PROCESS VARIABLES & INJECTION UNIT 1 & INJECTION UNIT 2 \\
\hline Injection pressure (bar) & 1000 & $400 / 400 / 300(3$ steps $)$ \\
\hline Holding pressure (bar) & 400 & 300 \\
\hline Holding time (s) & 2,5 & 2 \\
\hline Injection flow $\left(\mathrm{cm}^{3} / \mathrm{s}\right)$ & 80 & $30 / 25 / 20(3$ steps $)$ \\
\hline Temperature $\left({ }^{\circ} \mathrm{C}\right)$ & $180-210$ & 230 \\
\hline Cooling time $(\mathrm{s})$ & 25 & 20 \\
\hline
\end{tabular}

\subsection{Mechanical characterization of the composites and over injected samples}

The mechanical characterization was carried out according to ISO 527 in order to observe the influence of the coconut fiber on the tensile strength properties of the composites. The samples were analyzed with and without the addition of the coupling agent. Tests were conducted on a universal test machine Emic Model DL 2000 at a strain rate of $1 \mathrm{~mm} / \mathrm{min}$. All the ten samples were conditioned in an oven for 40 hours at a temperature of $23^{\circ} \mathrm{C}$ prior to testing.

\subsection{Digital image correlation}

The DIC is a measurement technique capable of correlating mechanical test results (i.e. a tensile test) to the amount of strain at each point of an analyzed structure, providing a better analysis of the mechanical behavior of a mechanical test. It consists of marking the surface of a certain area to be analyzed with random micropoints) and tracking its related movement during the mechanical test. The multi-injection sample was painted first with a white ink, forming the background and then it was sprayed with an airbrush black ink over the area of interest from Evolution Gmbh, under a pressure of 0.8 bar. Prior to the test, the DIC cameras identify each point of the analyzed region. Figure 3 presents one prepared sample being visualized by the DIC system at the ISTRA 4D software screen.

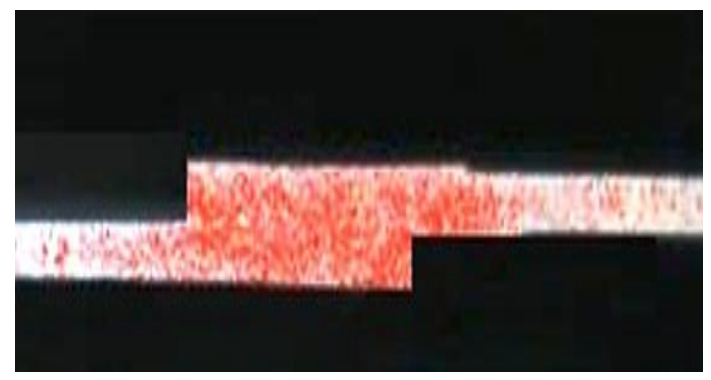

Figure 3: Example of sample ready for the DIC. Source: Authors.

Each red dot in Fig. 3 represents a recognized black ink spot which is tracked by the DIC system during the tensile/shear test. The DIC system quantifies the amount of displacement of each point during the test (picture after picture) and correlates it with the current applied load, informed by the tensile load test machine. By doing this, the system analyzes the amount strain and stress distribution of the region of interest of each sample for a better understanding of the resulting Single Lap Joint (SLJ) failure load (FL) and its mechanical behavior. The camera was set with $4 \mathrm{~Hz}$ to acquire the images of the analyzed area, registering a sequence of 4 pictures per second. The strain of the analyzed area was calculated via the Lagrange principal 
strain method, which measures the amount of movement of each sprayed point in $x$ and $y$ directions between the beginning and the end of the mechanical test. The DIC system used in this work was the Q-400-RT, from LIMESS GmbH, Krefeld, Germany composed of two cameras of 2 megapixels and the software from the same company.

The tensile load test machine used in this work was an Instron 4210, from INSTRON GmbH, Darmstadt, Germany following the reference in the standard DIN EN 1465, with displacement rate of $1 \mathrm{~mm} / \mathrm{min}$. This equipment was used to apply the load to the samples in a longitudinal way, resulting in shear load for the SLJ samples. The standard recommends the use of self-aligned grips and jaws or alignment shims and tabs, reducing misalignment and bending moment, providing a better condition for the tensile tests [14].

In this work the strength of adhesion between the polypropylene and composites with coconut fiber with or without additives were evaluated by DIC to verify the influence of the pure (simple) shear and to evaluate the behavior of the Lagrange vectors during the tensile stress of over injected materials.

\subsection{Morphological characterization of composites and samples}

To aid in the analysis of the coupling agent effect on the mechanical properties of the composites with coconut fiber and their influence on the tensile test of the composite samples, a Jeol Brand scanning electron microscope (SEM), model JSM - 6510LV, with tension ranging from 15 to $20 \mathrm{KV}$ was used. The sample composites were submitted to brittle fracture in liquid nitrogen around $-196^{\circ} \mathrm{C}$ and later analyzed by means of the fractured surfaces. The analysis of the external surfaces of the composites were evaluated observing the occurrence of defects in the form of irregularities that can favor the mechanism of adhesion by mechanical interlocking or as points of propagation of cracks during the tensile test. For this evaluation a Zeiss Scope A1 optical microscope (OM) with magnification of 200 times was used. The software for image processing was Axio Release 4.8.2.

\subsection{Contact angle test - wetting}

A wettability study using contact angle measurements was performed at the surfaces of the composite materials. Each measurement took into account a drop volume of $20 \mu \mathrm{l}$ of deionized water that was repeated three times. The results were obtained by the average of the last 50 points after a stabilization time of $10 \mathrm{~min}$. The equipment used for the test was a Krüss - Drop Shape Analyzer DSA41.0.2.7.

\section{RESULTS AND DISCUSSION}

The analysis of mechanical properties of the composites associated with both microscopy and DIC are discussed in terms of tensile strength of the overmolded joint and the stress distribution analysis of the overlap region.

\subsection{Mechanical characterization}

The mechanical tests were applied to the samples injected with composites and in the over-injected samples to evaluate the adhesion strength. The tensile strength of the polypropylene, coconut fiber and composites are shown in Table 3.

Table 3:Tensile strength results for the formulations studied.

\begin{tabular}{l|l}
\hline MATERIALS & YIELD STRENGTH (MPA) \\
\hline PP - EP440 L* & $17.18 \pm 0.12$ \\
\hline Coconut Fiber (CF) & $100.9 \pm 25.7$ \\
\hline PPCF & $16.95 \pm 0.29$ \\
\hline PPOCA100 & $22.35 \pm 0.32$ \\
\hline PPO18507 & $17.41 \pm 0.22$ \\
\hline PPCM & $16.17 \pm 0.29$ \\
\hline
\end{tabular}

* PP- EP 440 L was submitted to an extrusion in the same conditions of composites to injection of samples. 
The yield strength value for the coconut fiber (FC) was more than five times higher (absolute values) when compared with the pure polymer matrix. Analyzing the results for the composites, the best configuration was obtained using Orevac CA 100 (indicated as PPOCA100 in Table 3). A hypothesis for this result, based on some similar research, is that the participation of the coupling agent served to intensify the interaction with the fibers through strong covalent bonds or even through secondary interactions, resulting in a better interfacial adhesion between the coconut fiber reinforcement with the polymer matrix [15;16]. In the tests using composites with Orevac 18507 and Cesa ${ }^{\circledR}$ Mix, which have a polyethylene base, the interaction of the additive with the heterophasic polypropylene matrix was not satisfactory, and no significant variations were observed in the values of tensile strength in relation to the composite without a coupling agent. The increased stiffness in the composites with coconut fibers can be attributed to the hindrance of movement of the polymer matrix chains due to the strong interaction of the additive reacting with the free $\mathrm{OH}-$ on the fiber surface. This behavior has been observed in studies using vegetable fibers with polypropylene composites in particular [16]. Commonly, the effect of a coupling agent can be better observed at higher stresses when measuring the tensile strength, because a strong interface is crucial [17]. In fact, this behavior was more visible in PPOCA100 as shown in Figure 4 including more resistance to an elongation at break.

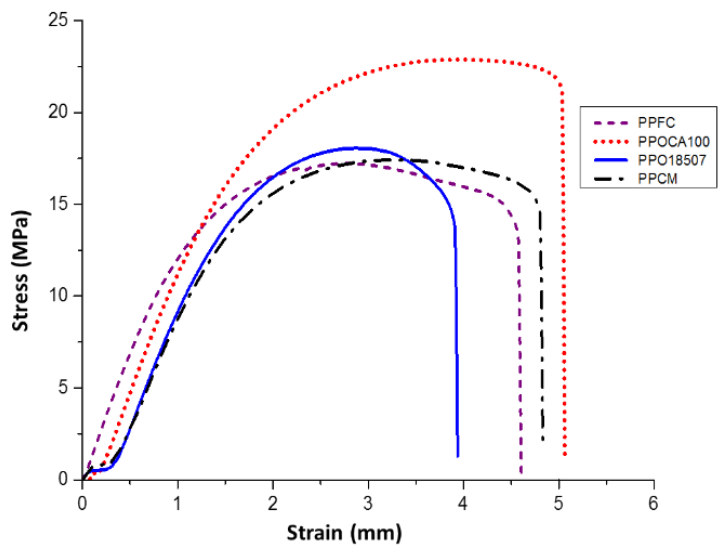

Figure 4: Graph of Stress Strain of the composites.

The mechanical tests showed that all the samples failed on the composite probably due to crack propagation in the region next to the overlap, indicating that there was a good adhesion among dissimilar materials. It was observed also that the PPCA100 composite presented an adhesion force which was slightly higher than other samples (including the sample without any additive). As presented in Figure 5, in this composite the fiber with the polymer matrix interacted better, enhancing the resistance to rupture in the zone close to the overlap.

\subsection{Morphological analysis of the composites}

For a better understanding of the results obtained from the mechanical tests, associated to the reinforcement theory, the samples surfaces were analyzed using SEM and OM. The images in Figure 5 show the fracture region of the composite surfaces.

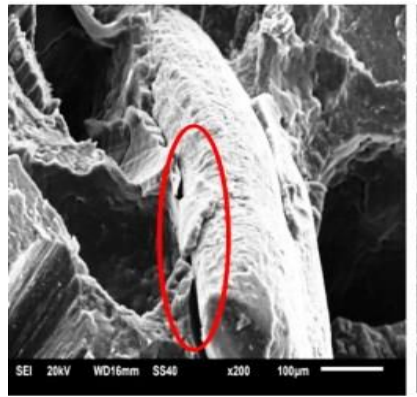

(a) PPCF

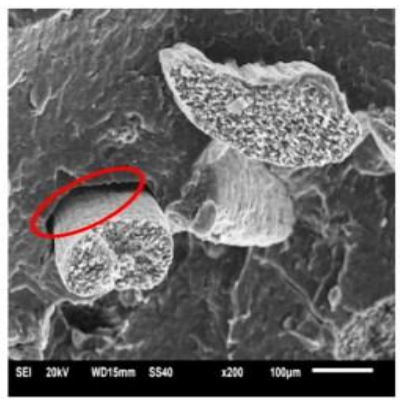

(b) PPCM

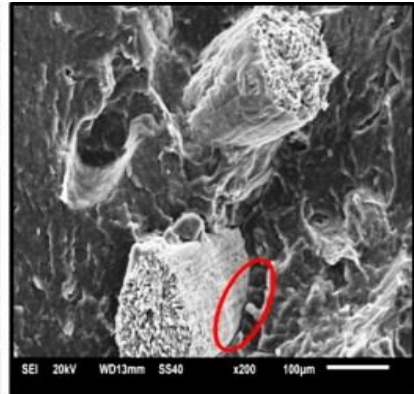

(c) PPO18507

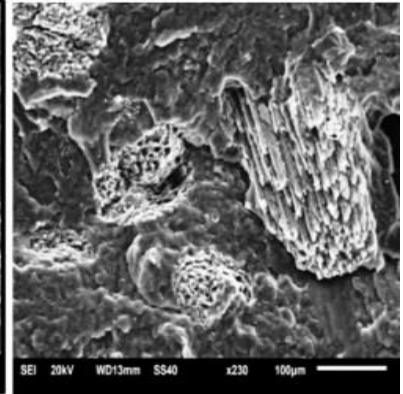

(d) PPOCA100

Figure 5: SEM images of the composite surfaces. (a) CF sample without additives; (b) with Cesa ${ }^{\circledR}$ Mix; (c) with Orevac 
When the material was tensile stressed, part of the load was absorbed by the fiber and thus increased the tensile strength of the composite [18]. If the adhesion between fiber and matrix is strong, the fibers break, showing that the interface is more resistant than the fiber. When the interaction is weak, as shown in the red circles, the fibers cannot assume full strength, and part of these fail to adhere with the matrix. Figure 5(a) shows the presence of voids and fiber pull-outs in the composite without additive, which may indicate the existence of a low affinity of the polymer matrix with the coconut fibers. These voids can occur due to the incomplete wetting of the resin on fibers, forming air bubbles (or pores) that can be trapped due to the high viscosity of the resin or due to the presence of volatile compounds that are released in the injection process [19].

The image in Figure 5(b) indicates a partial adhesion to the composite using Cesa ${ }^{\circledR}$ Mix because there were voids in the interfacial region between the fiber and the matrix, but it still exhibited a porous fracture surface of the fiber. Similar behavior can be observed for the compound with Orevac 18507 in Figure 5(c), where some regions with poor adhesion and fiber pull-out were observed, however, there is some evidence of partial adhesion. It was not possible to observe phase segregation between the HDPE contained in these coupling agents and the PP polymer matrix, indicating an apparent compatibility of the materials. Figure 5(d) presented shear of the fibers with no signs of pulling out of the polymer matrix, supporting the results of superior mechanical properties in this composite. The SEM results complement the mechanical characterization study because the additive samples showed an increase in tensile strength of up to $24 \%$ in relation to the PPFC composition and this is in agreement with results of other authors $[11 ; 17 ; 20]$. In line with Figure 6 (a,b,c,d), an optical reflection microscopy of the composites, a smoother surface with fewer defects, such as surface irregularities can be observed in the composites with added coupling agents.

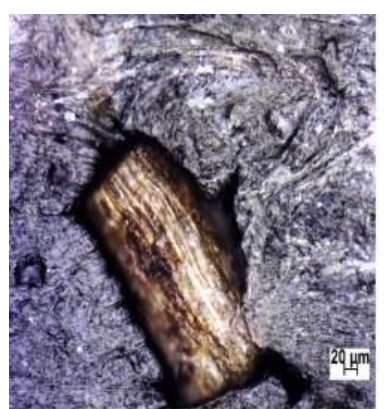

(a) PPCF

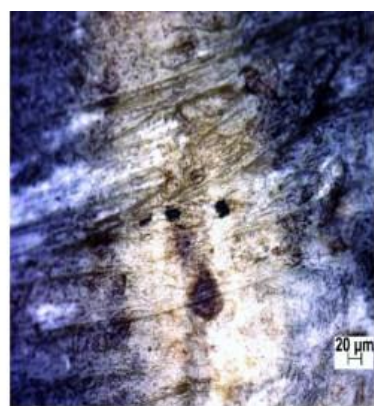

(b) PPCM

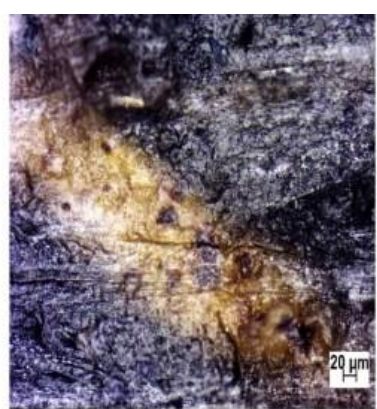

(c) PPO18507

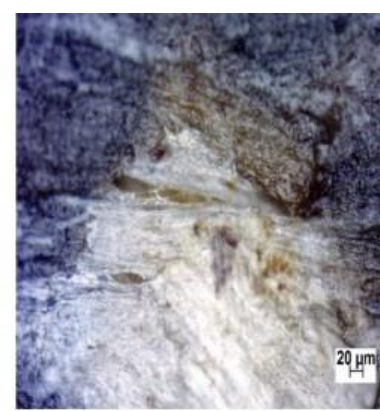

(d) PPOCA100

Figure 6: Reflection optical microscopy of the surfaces of the composites.

The low interfacial adhesion is associated to the low polarity and chemical affinity between the matrix and the vegetable fiber, which causes the formation of voids/pores in the interface that can compromise the mechanical performance of the composites [21]. This was verified in the tensile test result of the PPFC composite that was slightly lower than the PPOCA100 composite. According to Fig. 6 (a), the composite without a coupling agent, grooves were observed at the interface between the fiber and the polymer matrix, indicating low adhesion of the fiber with the polymer, which can act as a stress concentrator region [6].

\subsection{Composite contact angle measurements}

Figure 7 shows contact angle results, that was very close to each other, being the higher value presented by the PPFC sample. It can be seen that the composites with a coupling agent presented lower contact angle that is, a higher wettability, which is related to a more effective adhesion of the coconut fiber with the polymer matrix. This result is in agreement with the with the images obtained both OM and SEM and is in agreement with the results of the mechanical tensile test. 


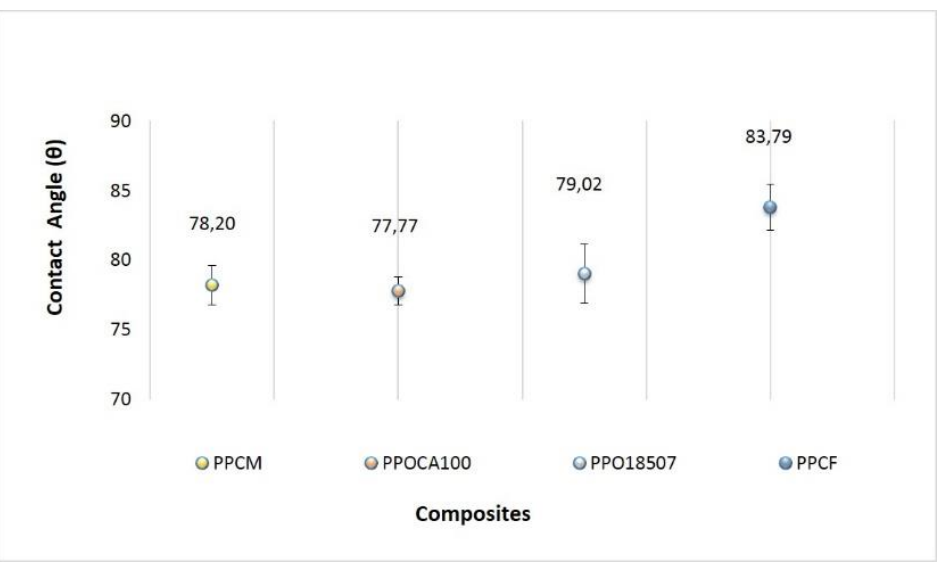

Figure 7: Contact angle of the composite materials.

According to results from literature, the polymer-fiber interface is improved with the use of coupling agents (CAs), whose function is to promote chemical bonds, as covalent, secondary (acid-base) or hydrogen, between the phases of the polymer matrix and the fiber by changing the surface energy of the reinforcement, thus allowing a more efficient wetting of the fiber with the polymeric matrix $[17 ; 21 ; 22]$. Based on the contact angle measurement, it is possible to note that the use of the coupling agent was efficient, leading to a reduction in the composite contact angles. The PPOCA100, which had the lowest contact angle, was the most effective in the union of the fibers with the polymer matrix. Instead, the composite without coupling agent presented a higher angle of contact as well as lower tensile strength.

\subsection{Digital image correlation - DIC}

In most cases of tensile tests involving SLJ with ductile or low yield strength substrates, the failures found resulted from peeling stresses (mainly secondary forces) related to the bending moment at the edges of the overlap region $[23 ; 24 ; 25 ; 26]$. In these cases, it is common to detect crack propagations through the overlap region with the aid of the DIC technique [23;25], as can be seen from the results shown in Figure 8 (a,b,c,d).

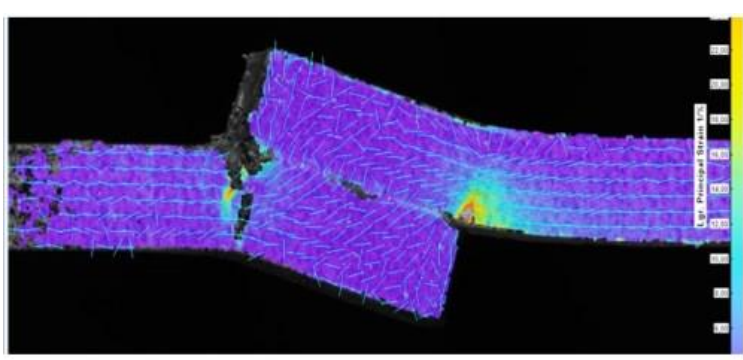

(a) PPFC

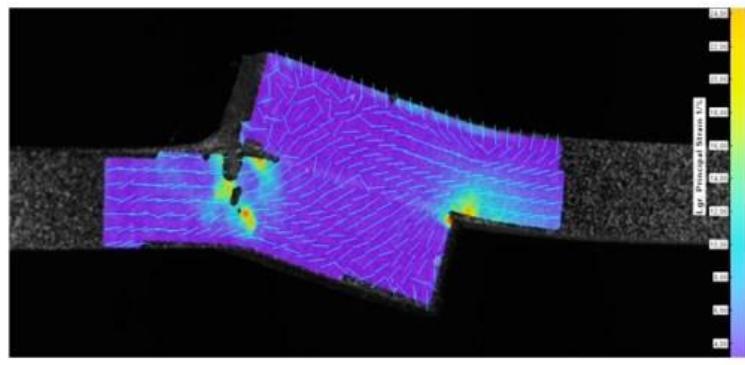

(c) PPO18507

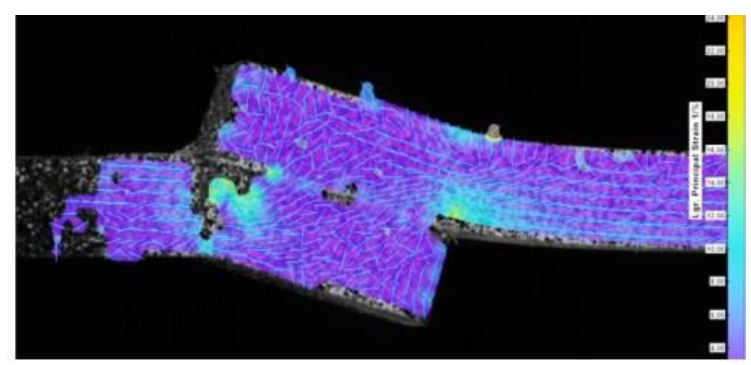

(b) PPCM

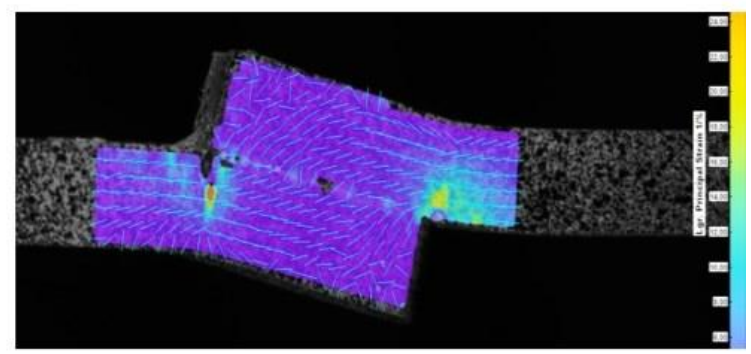

(d) PPOCA100

Figure 8: Stress state analysis of the SLJs through DIC. Note cracks occurring in the direction of the composite and the visualization of Lagrange vectors.

In this work, however, it was found that the addition of coupling agents between the fiber and polymer matrix were effective because they prevented the failure by incidence of peeling stress in the region of overlap and consequent crack propagation located at the interface. The failure observed in the mechanical tests 
was a consequence of the bending moment derived from the geometric aspect of the specimen (i.e. the closer to the overlap region, the greater the bending moment) associated to the substrate necking (reduction in the transversal section due to plastic strain). In Figure 8 it can be seen that the overlapping region, despite deflected, maintained a uniform load distribution along the adhesion interface. Additionally, the region of the substrate that was close to the overlap region, due to the bending moment, presented a compression zone (indicated by "A" in Figure 9) and a traction zone (indicated by "B" in the same Figure 9). As a consequence of this stress state, a crack propagated perpendicular to the substrate, leading the sample to failure, preferentially on the side of the composite. The Lagrange vectors indicated specimen necking on the free length of the substrate (outside the overlap region). In addition, the results indicated a transfer of tensile loads converted into shear along the overlap region due to the geometric aspect of the samples.
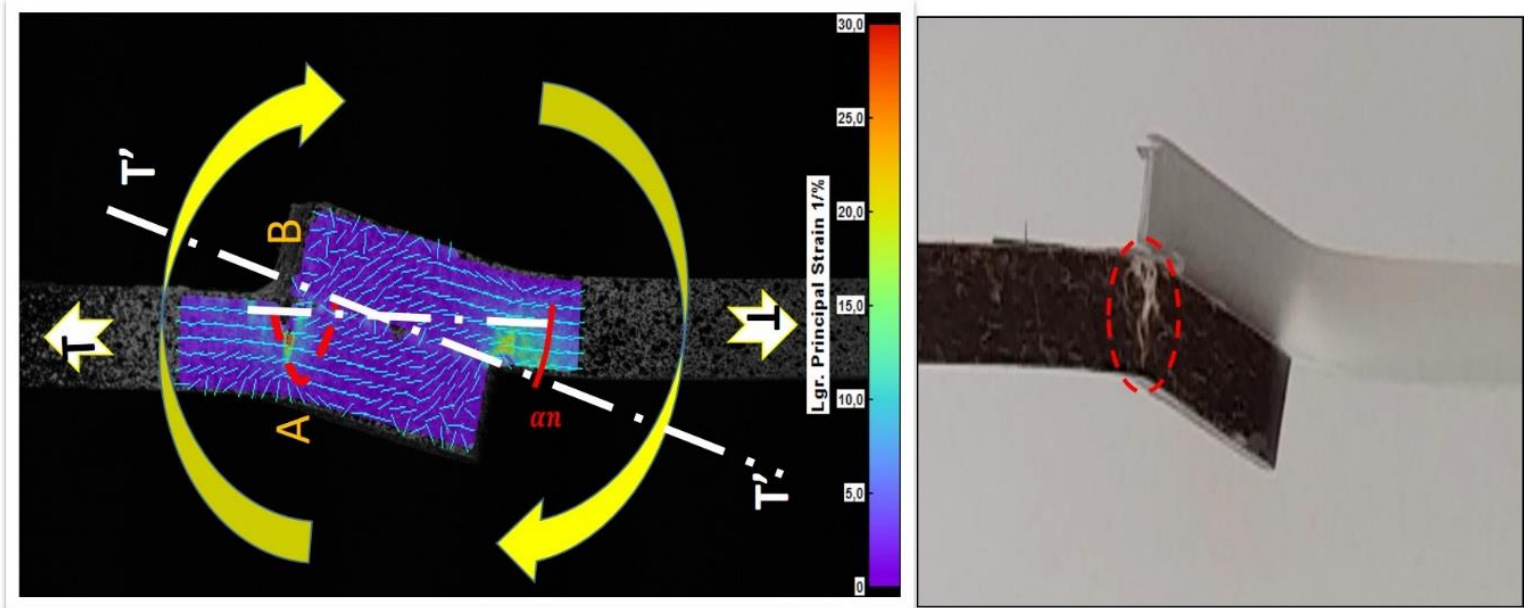

Figure 9: DIC stress state analysis of the PPOCA100 composite.

The failure location observed in this work agrees with the bending moment theory of Tsai-Morton [27], as explained by SILVA and NUNES [28]. The SLJ geometric aspect favors the generation of a bending moment, since the tensile stress $\mathrm{T}$ is converted into $\mathrm{T}^{\prime}$ due to the misalignment of the sample, as shown in Figure 11. In addition, the PPOCA100 sample, due to the higher failure load, was submitted to a greater bending moment $\mathrm{M}_{0}$, as can be verified by the Tsai-Morton Equations (1) and (2) (see TSAI-MORTON, 1994) [27].

$$
M_{0}=\mathrm{T}\left[\alpha_{n} * l-w_{1}\right]
$$

where $\mathrm{M}_{0}$ is the bending moment; $\alpha$ is the misalignment coefficient (deflection angle); $\mathrm{T}$ is the tension load; 1 is the adherend free length factor; and w1 is the vertical displacement (of the analyzed point). The deflection angle, $\alpha$, shown in Figure 10, can be calculated by Equation (3):

$$
\alpha_{n}=\frac{t+t_{a}}{2 l+c}
$$

where $t$ is the adherend thickness; $t_{a}$ is the adhesive layer thickness; and $c$ is half of the overlap length. In this work, $t_{a}$ was considered null as no adhesive was used.

The fact that all samples behaved the same regarding substrate deflection and the absence of peeling stress failure indicated that even without the coupling agent, the adhesion of the dissimilar materials were effective.

Analyzing the location and failure mode in this experiment, the overlap region can be considered a reinforcement of the joint, unlike some adhesion cases of joining dissimilar materials, such as welding of metals, usage of rivets and screws in solid substrates, where the adhesion region is considered as a defect in the part or a stress concentrator point.

The results using the DIC technique confirm that the coupling agent CA100 was the most effective in binding the fiber with the polymer matrix, in agreement with the mechanical tests results of other composites and optical and scanning electron microscopies. The surface of the composite with a more homogeneous appearance and the less evidence of defects such as pores and other irregularities may have favored the tensile strength of the joint because it had fewer stress concentrators at the joining and the failure regions, as revealed by the DIC test. 
In spite of a good adhesion between the polypropylene and the composites, the influence of the bending moment and its secondary forces over the stress concentrator points, presented in Figure 9, led the samples to fail at the region next to the overlap, initially at the composite side. This study may contribute to the dissemination of the adhesion technology of dissimilar materials, increasing the possibility of using composites with natural fibers in multi-component injection processes.

\section{CONCLUSIONS}

Understanding the effects of the coupling agent on the adhesion strength of thermoplastic composites overinjected on a polypropylene polymeric matrix is a task that requires very careful study and experiments. In this work three different coupling agents were used to modify the surface tension between a fiber and polymer matrix in different ways. We found that the Orevac CA100 was the most efficient among the coupling agents analyzed, promoting a better interaction of the matrix with the coconut fiber. The PPOCA100 composite led to a significant increase in the tensile strength and a smaller contact angle, which favored the wetting and the adhesion property of the materials. Changes in the morphology of the PPFC composite without a coupling agent caused imperfections in the composite surface that may have acted as stress concentrator points leading to fracture. By means of the Digital Image Correlation (DIC), the Lagrange vectors indicated a high shear stress condition in the joining of the two adherends for all the cases, which is an interesting condition for bonded joints. The failure took place at the edges of the overlap area, in the adherends, due to the bending moment and its related secondary forces (i.e. peeling stresses and normal forces) generating stress concentrator points. In joints using ductile materials, usually a failure happens due to peeling stress and crack propagation from the edges to the center of the interface. This was not the case in the joints used in this work, indicating good adhesion between dissimilar materials. The increased stiffness in the coconut fiber composites led to failure preferably on the side of the composite before the peeling stresses forces happened.

\section{ACKNOWLEDGEMENTS}

The present work was supported by SENAI CIMATEC, Federal University of Bahia, via the Graduate Program in Industrial Engineering and the German Welding and Joining Institute ISF from RWTH University. We are also thankful for the support of the Brazilian National Research Council, CNPq Grant Nos. 300938/2012-8, 471546/2012-7 and 304705/2015-2.

\section{BIBLIOGRAPHY}

[1] BANERJEE, A. G., LI, X., FOWLER, G., et al., "Incorporating manufacturability considerations during design of injection molded multi-material objects", Research in Engineering Design, v. 17, pp. 207-231, 2007, ISBN: 09349839 (ISSN), ISSN: 09349839, DOI: 10.1007/s00163-007-0027-9.

[2] GOUKER, R. M., GUPTA, S.K., BRUCK, H.A., et al., "Manufacturing of multi-material compliant mechanisms using multi-material molding", International Journal of Advanced Manufacturing Technology, v. 30, n. 11-12, pp. 1049-1075, 2006. ISSN: 02683768, DOI: 10.1007/s00170-005-01524.doi:10.1007/s00170-005-0152-4.

[3] GUPTA, S. K., Overview of In-Mold Assembly Research at the Advanced Manufacturing, Lab. Maryland: [s.n.], 2011.

[4] KLEMARCZYK, P., "The mechanics of coatings", In: Adhesion Science and Engineering, 1 ed., (2002) 847-867, Toronto, Cana-da, DOI:10.1016/B978-044451140-9/50019-6.

[5] SILVA, L. F. M. D., CARBAS, R.J.C., CRITCHLOWB, G.W., et al., "Effect of material, geometry, surface treatment and environment on the shear strength of single lap joints", International Journal of Adhesion and Adhesives, v. 29, n. 6, pp. 621-632, 2009. ISBN: 0143-7496, ISSN: 01437496, DOI: 10.1016/j.ijadhadh.

[6] PACKHAM, D. E., "Surface roughness and adhesion", In: Surfaces, Chemistry and Applications, 1 ed., Elsevier B.V., 2003. 317-349 p. DOI: 10.1016/B978-0-444-51140-9.50007-X.

[7] POCIUS A.V., Chemistry and Applications, In: M. CHAUDHURY (Org.), 2002 ed. Bethlehem, PA I81 05 U.S.A: M., Chaudhury, 2002, 1226 p.

[8] WOOL, R. P., "Adhesion at polymer-polymer interfaces: A rigidity percolation approach", Comptes Rendus Chimie, v. 9, n. 1, pp. 25-44, 2006. ISSN: 16310748, DOI: 10.1016/j.crci.2005.04.008.

[9] GUPTA, S. K., FOWLER, G. T., “A Step Towards Integrated Product / Process Development of Molded 
Multi-Material Structures", In: The fifth International Symposium on Tools and Methods for Concurrent Engineering, p. 1-12, Lausanne, Switzerland, April, 2004.

[10] AWAJA, F., GILBERT, M., GEORGINA, K., et al., “Adhesion of polymers”, Progress in Polymer Science, Oxford, v. 34, n. 9, p. 948-968, 2009. ISBN: 0079-6700, ISSN: 00796700, DOI:

10.1016/j.progpolymsci.2009.04.007.

[11] OWEN, M. J., CORNING, D., MIDLAND, C. "Coupling Agents : Chemical Bonding at Interfaces", Surfaces, Chemistry and Applications. Midland, USA, Elsevier B.V., 2002. p. 403-431. DOI: 10.1016/B9780-444-51140-9.50009-3.

[12] SUTTON, M. A., SCHREIER, H., ORTEU, J.-J. "Image Correlation for Shape, Motion and Deformation Measurements", Springer Science \& Business Media., Columbia, SC: Springer, 2009. ISBN: 978-0-387-78746-6, ISSN: 1098-6596.

[13] LU, H., ZHANG, X., KNAUSS, W. G. "Uniaxial, shear, and poisson relaxation and their conversion to bulk relaxation: Studies on poly(methyl methacrylate)", Polymer Engineering \& Science, [s.1.], v. 37, $\mathrm{n}^{\circ}$ 6, p. 1053-1064, 1997. ISBN: 1548-2634, ISSN: 0032-3888.

[14] GUO, S., DILLARD, D. A., PLAUT, R. H., "Effect of boundary conditions and spacers on single-lap joints loaded in tension or compression", International Journal of Adhesion and Adhesives, v. 26, n. 8, p. 629-638, 2006. ISBN: 0143-7496, ISSN: 01437496, DOI: 10.1016/j.ijadhadh.2005.09.005.

[15] TECHAWINYUTHAM, L., FRICK, A., SIENGCHIN, S. "Polypropylene/Maleic Anhydride Grafted Polypropylene (MAgPP)/Coconut Fiber Composites", Advances in Mechanical Engineering, v. 8, N ${ }^{\circ}$ 5, p. $1-$ 9, 2016. ISSN: 1687-8140, DOI: 10.1177/1687814016645446.

[16] SAHEB, D. N., JOG, J. P., "Natural Fiber Polymer Composites : A Review", Advances in Polymer Technology, v. 2329, November, 1999, p. 351-363, 2016. DOI: 10.1002/(SICI)1098-2329(199924)18.

[17] CATTO, A. L., STEFANI, B.V., RIBEIRO, V.F., et al., "Influence of Coupling Agent in Compatibility of Post-consumer HDPE in Thermoplastic Composites Reinforced with Eucalyptus Fiber", Materials Research, v. 17, n. 1, pp. 203-209, 2014. ISSN: 15161439, DOI: 10.1590/S1516-14392014005000036.

[18] LOMELÍ RAMÍREZ, M. G., SATYANARAYANA, K.G., IWAKIRI, S., et al., "Study of the properties of biocomposites. Part I. Cassava starch-green coir fibers from Brazil”, Carbohydrate Polymers, v. 86, pp. 1712-1722, 2011. ISSN: 01448617, DOI: 10.1016/j.carbpol.2011.07.002.

[19] TANOBE, V. O., et al., "A comprehensive characterization of chemically treated Brazilian spongegourds (Luffa cylindrica)”, Polymer Testing, v. 24, n. 4, pp. 474-482, 2005. ISSN: 01429418, DOI: 10.1016/j.polymertesting.2004.12.004.

[20] ROBERTS, D. H., "Chemical coupling of polypropylene systems containing nonglass fillers", Journal of Vinyl and Additive Technology, v. 5, n. 4, pp. 231-234, 1999. ISSN: 1083-5601, DOI: 10.1002/vnl.10336.

[21] ZIMMERMANN, M. V. et al., "Influência do Tratamento Químico da Fibra de Bananeira em Compósitos de Poli(etileno-co-acetato de vinila) com e sem Agente de Expansão", Polímeros Ciência e Tecnologia, v. 24, n. 1, pp. 58-64, 2014. ISSN: 1678-5169, DOI: 10.4322/polimeros.2013.071.

[22] JOHN, M. J., ANANDJIWALA, R. D., "Recent Developments in Chemical Modification and Characterization of Natural Fiber-Reinforced Composites", Polymers and Polymer Composites, v. 16, N ${ }^{\mathrm{o}} 2$, p. 101113, 2008. ISBN: 0967-3911, ISSN: 09673911, DOI: 10.1002/pc.

[23] BAMBERG, P. A. M. G., et al., "Tensile Stress Analyses through Digital Image Correlation of Single Lap Joints of High Strength Steel and Aluminum Alloy Using Adhesive Bonding”, Materials Science Forum, v. 879, p. 363-368, 2016. DOI: 10.4028/www.scientific.net/MSF.879.363.

[24] EUSTÁQUIO, H. M. B., et al., "Caracterização de Compósitos de Polietileno de Baixa Densidade (PEBD) e Fibras de Coco (FC): Efeito do Tratamento Superficial da Fibras e do Agente de Compatibilização", In: $11^{\circ}$ Congresso Brasileiro de Polímeros, pp. 5603-5608, Campos do Jordão,11 ${ }^{\circ}$ CBPOL, 2011.

[25] PACKHAM, D. E., Handbook of adhesion technology, 2 ed. UK England, The Atrium, Southern Gate, Chichester, West Sussex PO19 8SQ, 2005. 570 p. ISBN: 9780471808749, DOI: 10.1002/0470014229.

[26] KARACHALIOS, E. F., ADAMS, R. D., SILVA, L. F. M. D., "Single lap joints loaded in tension with ductile steel adherends", International Journal of Adhesion and Adhesives, v. 43, pp. 81-95, 2013. ISBN: 0143-7496, ISSN: 01437496, DOI: 10.1016/j.ijadhadh.2013.01.017.

[27] TSAI, M. Y., MORTON, J., “Three-dimensional deformations in a single-lap joint”, The Journal of Strain Analysis for Engineering Design, v. 29, n. 2, pp. 137-145, 1994. ISSN: 0309-3247, DOI: 10.1243/03093247V292137. 
[28] SILVA, T. C., NUNES, L. C. S. "A new experimental approach for the estimation of bending moments in adhesively bonded single lap joints", International Journal of Adhesion and Adhesives, v. 54, pp. 13-20, 2014. ISSN: 01437496, DOI: 10.1016/j.ijadhadh.2014.04.006.

\section{ORCID}

Luciano Pisanu

Josiane Dantas Viana Barbosa

Marcio Luis Ferreira Nascimento

Ricardo Alves de Sousa

Pedro de Andrade Mato Grosso e Pedreira Bamberg https://orcid.org/0000-0002-2472-0382

Bernd Marx

Alexander Schiebahn https://orcid.org/0000-0001-7727-6978

https://orcid.org/0000-0002-7423-5326

https://orcid.org/0000-0001-5030-7500

https://orcid.org/0000-0002-5848-6424

https://orcid.org/0000-0003-0279-3537

https://orcid.org/0000-0001-8427-6765 